\title{
Evaluation of erythrocyte autoantibodies with flow cytometric phagocytosis assay
}

\author{
Shoichi Ito, Tomoko Hishinuma, Yoshiko Ogiyama, Tomomi Asano, \\ Haruka Kagaya, Michiyo Irino, Hideya Hasegawa, Hiroshi Shimizu, \\ Kenneth E. Nollet, Masayoshi Minegishi, Hitoshi Ohto
}

\begin{abstract}
Aims: Cellular assays such as the monocyte monolayer assay have been used to evaluate the clinical significance of antibodies to red blood cells (RBCs). Flow cytometry (FCM) has also been applied to antibody screening and diagnosing autoimmune hemolytic anemia (AIHA). Methods: RBC eluate from 131 patients with positive direct antiglobulin tests, along with three human monoclonal antibodies (two anti-D and one anti-Dib) were used to evaluate a new FCM two-color phagocytosis assay using markers that bind RBCs and monocytes. Dual-positive event percentages were compared with antibody titers and trimmed mean fluorescence intensity (MFI) from the 131 eluates and three monoclonal antibodies. Results: Percent positive by the FCM phagocytosis assay correlated well $\left(R^{2}=0.755\right)$ with trimmed-MFI in serial dilutions of two human IgG1 monoclonal antibodies, anti-D and
\end{abstract}

Shoichi Ito ${ }^{1}$, Tomoko Hishinuma ${ }^{1}$, Yoshiko Ogiyama1, Tomomi Asano ${ }^{1}$, Haruka Kagaya ${ }^{1}$, Michiyo Irino ${ }^{1}$, Hideya Hasegawa' ${ }^{1}$, Hiroshi Shimizu', Kenneth E. Nollet² ${ }^{2}$ Masayoshi Minegishi ${ }^{3}$, Hitoshi Ohto ${ }^{2}$

Affiliation: ${ }^{1}$ Japanese Red Cross Tohoku Block Blood Center, Sendai, Miyagi, Japan; ${ }^{2}$ Department of Blood Transfusion and Transplantation Immunology, Fukushima Medical University, Fukushima, Japan; ${ }^{3}$ Japanese Red Cross Fukushima Blood Center, Fukushima, Japan.

Corresponding Author: Hitoshi Ohto, MD, PhD, Department of Blood Transfusion and Transplantation Immunology and Department of Advanced Cancer Immunotherapy, Fukushima Medical University, Hikariga-oka, Fukushima City, Fukushima, 960-1295, Japan; Email: hit-ohto@fmu.ac.jp

Received: 16 March 2018

Accepted: 11 April 2018

Published: 27 April 2018
anti-Dib, and 131 clinical samples with titers ranging from 2 to 2048 . IgG2 antibodies showed lower phagocytosis relative to titers and MFI associated with these antibodies. Conclusion: The FCM phagocytosis assay can be used to evaluate AIHA-associated antibodies, with great potential to standardize immunohematology testing, especially in regard to establishing the clinical significance of RBC alloantibodies.

Keywords: Direct anti-globulin test, Flow cytometry, IgG subclass, Phagocytosis

\section{How to cite this article}

Ito S, Hishinuma T, Ogiyama $\mathrm{Y}$, Asano T, Kagaya $\mathrm{H}$, Irino M, Hasegawa H, Shimizu H, Nollet KE, Minegishi M, Ohto H. Evaluation of erythrocyte autoantibodies with flow cytometric phagocytosis assay. Int J Blood Transfus Immunohematol 2018;8:100039Zo2SI2018.

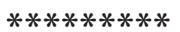

Article ID: 100039Z02SI2018

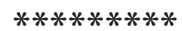

doi:10.5348/100039Zo2SI2018OA

\section{INTRODUCTION}

Red blood cells (RBCs) sensitized with IgG alloantibody are subject to removal and destruction via the mononuclear phagocyte system, which includes splenic macrophages. Among IgG subclasses (1-4 which differ in their constant regions), IgG3 has the strongest complement activity whereas IgG4 has the least. Blood monocytes migrate through vessel walls and differentiate 


\section{EDORiUM Journals}

www.ijbti.com

into macrophages that express Fc $\gamma \mathrm{RI}$ receptors with high affinity for IgG1 and IgG3. Antibody-sensitized RBCs can be bound via the Fc $\gamma \mathrm{R}$ I receptor and subsequently phagocytosed by macrophages [1]. Conversely, IgG2coated RBCs are hardly phagocytosed due tothe low affinity of IgG2 for the Fc $\gamma \mathrm{R}$ I receptor [2].

The monocyte monolayer assay (MMA) is an established tool for evaluating the clinical significance of blood group alloantibodies, thus informing the decision to transfuse, or not, RBCs incompatible with antibodies to high-incidence antigens [3]. RBCs with warm direct antibody positivity may vary in regard to autoantibody titer and IgG subclass $[4,5]$. In this study, to quantify associations between antibody titer, IgG subclass, and phagocytic activity, we developed a flow-cytometry (FCM) phagocytosis assay, and demonstrated its utility using clinical samples from direct-antibody test (DAT) positive RBCs and pooled monocytes.

\section{MATERIALS AND METHODS}

\section{Clinical samples, eluates from red blood cells, and antibody titration}

A total of 131 eluates were derived from warm DATpositive RBCs samples sent to Japanese Red Cross Society (JRCS) Tohoku Block Center to evaluate the clinical significance of their autoantibodies. No patients had been transfused within three months prior to sampling. The study protocol was approved by JRCS Blood Service Headquarters (approval \#Red-74).

Eluates from RBCs were obtained using Ortho DT Eluates II (Ortho Clinical Diagnostics, NJ, USA) according to the manufacturer's instructions. Briefly, 1 mL of patient RBCs was washed with phosphate-buffered saline (PBS), then suspended in $1 \mathrm{~mL}$ of PBS, to which 2 $\mathrm{mL}$ of DT Eluates II were added. After mixing, the cell suspension was incubated for five minutes at $37^{\circ} \mathrm{C}$, and finally eluates were obtained after centrifugation.

Eluate aliquots of $100 \mu \mathrm{L}$ were mixed with $100 \mu \mathrm{L}$ of $3 \%$ suspensions from a 3-cell panel mixture of R1R2 (DCe/DcE) RBCs, and low-ionic strength solution (LISS) was added for the indirect antiglobulin test. Antibody titer was determined by reactivity in the most diluted tube in two series of titrations with PBS.

\section{IgG subclass}

IgG subclass was determined by flow cytometry as described previously [6], with partial modification. Briefly, $2 \mu \mathrm{L}$ of sedimented RBCs, $100 \mu \mathrm{L}$ of eluate, and $100 \mu \mathrm{L}$ of LISS were mixed and incubated at $37^{\circ} \mathrm{C}$ for 15 minutes. After washing three times with PBS, $40 \mu \mathrm{L}$ of $0.5 \%$ solution of sensitized RBCs and $100 \mu \mathrm{L}$ of 10 -fold diluted fluorescence-conjugated sheep anti-human-IgG1, IgG2, IgG3, IgG4 (The Binding Site, Birmingham, UK) or $6 \%$ albumin were added. After incubating for 30 minutes in the dark at room temperature, cells were washed once with $4 \mathrm{~mL}$ of phosphate buffered saline (PBS) to remove unbound antibodies. Flow cytometry (FCM) analysis was done using a FACS Calibur (Becton Dickinson, Tokyo). A total of 10,000 events for each sample were acquired.

\section{Estimation of autoantibody-binding to RBCs}

To estimate autoantibody binding to RBCs, $50 \mu \mathrm{L}$ of eluate, $25 \mu \mathrm{L}$ of $2 \%$ RBC suspension and $50 \mu \mathrm{L}$ of LISS were mixed and incubated at $37^{\circ} \mathrm{C}$ for 15 minutes. After washing 3 times with PBS, $100 \mu \mathrm{L}$ of fluorescencelabelled F (ab')2 sheep anti-human IgG(H+L) (Abliance, Compiege, France) was added to the RBCs and incubated for 30 minutes at room temperature. The pellet was vigorously stirred before cytometric analysis. The binding intensity of autoantibodies was estimated using the trimmed mean fluorescence intensity (MFI) value.

\section{Phagocytosis assay with FCM}

(1) Fluorescence labeling of RBCs

For labeling, $500 \mu \mathrm{L}$ of $0.2 \%$ PKH26 (Red Fluorescence Cell Linker Kit, SIGMA-ALDRICH, Darmstadt, Germany) was added to $1.3 \mu \mathrm{L}$ of washed 3-cell RBC sediment, and incubated for five minutes at room temperature. After washing, RBCs were suspended in $25 \mu \mathrm{L}$ of RPMI-1640 (DS Pharma Medical, Osaka, Japan).

(2) Autoantibody sensitization to RBCs

Autoantibody eluate and LISS (50 $\mu \mathrm{L}$ each) were added to $25 \mu \mathrm{L}$ of $\mathrm{PKH} 26$-labeled RBC suspension, and incubated at $37^{\circ} \mathrm{C}$ for 15 minutes. After washing three times, $500 \mu \mathrm{L}$ of RPMI-1640 was added to the tube to prepare an autoantibodysensitized and fluorescent RBC suspension.

(3) Pooled monocyte suspension

Mononuclear cells from ethylene diamine tetra acetic acid (EDTA)-anticoagulated whole blood from 20 healthy donors were separated by centrifugation over mononuclear cell separation reagent (Lymphoprep, Axis-Shield Poc As, Norway). Then, monocytes were purified using monocyte selection reagent (EasySep Human CD14 Positive Selection kit, Stem Cell Technologies, Canada) according manufacturer's instructions. Monocytes were finally suspended in RPMI at a concentration of $1,000 / \mu \mathrm{L}$.

(4) FCM phagocytosis

A mixture of $500 \mu \mathrm{L}$ of autoantibody-sensitized RBC suspension and $500 \mu \mathrm{L}$ of pooled monocyte suspension was stirred and incubated at $37^{\circ} \mathrm{C}$ in a $\mathrm{CO}_{2}$ incubator for one hour, and then supernatant was removed after centrifugation for three minutes at $3000 \mathrm{rpm}$. Thereafter, to hemolyze nonphagocytosed RBCs, $1 \mathrm{~mL}$ of hemolysis solution (Lysing Solution, Becton Dickinson, Tokyo) was 


\section{EDORIUM Journals}

added to the cell pellet and kept for 10 minutes at room temperature. After washing, monocytes were fluorescence-labeled with $25 \mu \mathrm{L}$ FITC Mouse Anti-Human CD14 (Becton Dickinson, Tokyo) at $4^{\circ} \mathrm{C}$ for 30 minutes. Monocytes and RBCs were detected by FITCfluorescence in FL1 and PKH26 fluorescence at FL2, respectively. Among 2,000 events per FITC fluorescence, the PKH-positive percentage was interpreted as a measure of phagocytosis.

Eluates obtained from DAT-negative RBCs were used as negative controls. Two human monoclonal IgG1 antibodies, anti-D (HIRO-3, JRCS, Tokyo) [7] and anti-Dib (JRCS) were used as positive controls, along with one human monoclonal IgG2 anti-D (JRCS) as a reference.

(5) Reproducibility of assays

To confirm the obtained results, we assayed three times using different monocytes sources and three human monoclonal antibodies, two anti-D and one anti-Dib, at a range of titers from 4 to 1,024 .

\section{Statistical analysis}

Statistical analyses were conducted using Microsoft Excel software (Microsoft Excel 2016, Microsoft, USA). Student's t-test was used to compare FCM-phagocytosis assays with different antibody titers. Trimmed mean was calculated by omitting the maximum and minimum $10 \%$ of obtained data. For figure 5, a logarithmic trendline was drawn using the above software. Statistical significance was set at $\mathrm{p}<0.01$.

\section{RESULTS}

\section{Preliminary assessment of the flow cytometry-phagocytosis assay}

Preliminary results using three human monoclonal antibodies are shown in Figures 1 and 2. The percentage of RBCs phagocytosed by monocytes was determined on the basis of double positivity for both markers.

For reproducibility, the percent positive measure of phagocytosis was repeated three times using two human monoclonal antibodies, one anti-D and one anti-Dib, without statistically significant differences at 8 antibody titers from 4 to 1,024 with coefficient of variance between 0.02 and 0.38 using an anti-D of subclass IgG1 and between 0.01 and 0.43 using an anti-Dib (data not shown).

As shown in Figure 2, similar phagocytosis results were obtained when monocytes obtained from 3 different pools of donors were used at a constant monocyte concentration of $1,000 / \mu \mathrm{L}$. Phagocytosis activity increased sharply at antibody titers of 32 and 64, and plateaued around 90\% at titers of 128 and 258 .

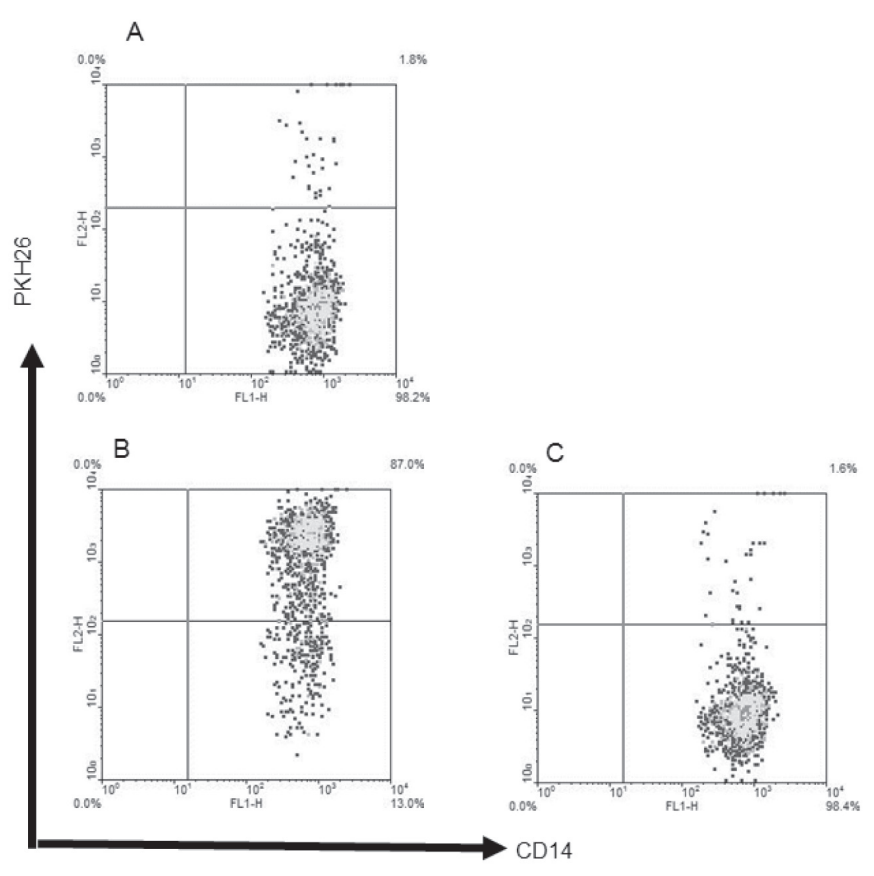

Figure 1: Events gated according to fluorescence intensity of CD14 (x axis) and PKH26 (y axis). (A) Negative control with RPMI-1640. Among total events, only $1.8 \%$ were gated as reactive. (B) Positive (87.0\%) flow cytometric phagocytic assay with human IgG1 monoclonal anti-D, with preparation of titer 256. (C) Negative (1.6\%) flow cytometric phagocytic assay with human IgG2 monoclonal anti-D, with preparation of titer 256.

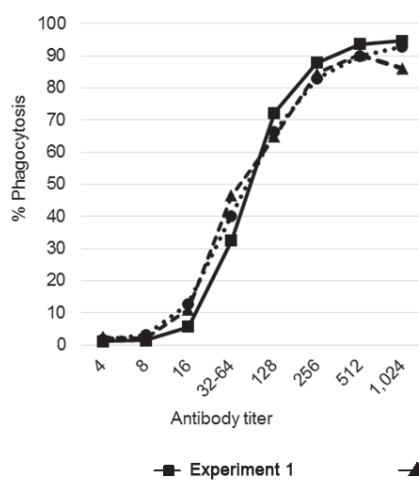

Figure 2(A and B): Representative reproducibility results from repeated assays. (A) Results of human IgG1 monoclonal anti-D. (B) Results of humanIgG1 monoclonal anti-Dib ${ }^{\text {b }}$.

\section{Comparison between antibody titer of eluates and FCM-phagocytosis assay}

Using 131 eluates from DAT positive RBCs, phagocytosed RBCs were compared with antibody titers of eluates. Trimmed means ranged between $1.4 \%$ and $3.7 \%$ at antibody titers from 2 to $16,14.6 \%$ at an antibody titer of $32,41.0 \%$ at an antibody titer of 64 , between $76.5 \%$ and $80.4 \%$ at antibody titers of 128 to 256 , and between $81.7 \%$ and $90.3 \%$ at antibody titers of 512 and above (Figure 3). Similar to the preliminary assessment, phagocytosed 


\section{EDORIUM Journals}

Int J Blood Transfus Immunohematol 2018;8:100039Z02SI2018. www.ijbti.com

percentages increased sharply at titer around 64, however the phagocytosis did not changed significantly at titers from 2 to 16. Moreover, phagocytosis percentages did not differ at antibody titers of 256 or more, as shown in Figure 3. Good correlation between antibody titer and percent phagocytosis is evident in Figure 4, along with two exceptional cases, in which lower phagocytosis of $4.1 \%$ and $6.2 \%$ was observed with higher titers of 256 and 1,024 .

\section{Comparison between MFI and phagocytic activity}

Trimmed MFI varied between 6.6 and 57.1 at antibody titers from 2 to 16, 108.3 at an antibody titer of 32, 213.2 at an antibody titer of 64, 472.0 at an antibody titer of 128, 747.6 at an antibody titer of 256, 1,285.3 at an antibody titer of 512, 1,852.3 at an antibody titer of 1,024, and 3,106.7 at an antibody titer of 2,048 (Figure 5). The lowest trimmed MFI value was 221.1 among samples in which FCM-phagocytosis activity of $60 \%$ or more.

The correlation coefficient $\mathrm{R}^{2}=0.755$ showed good correlation between autoantibody MFI, and FCMphagocytosis activity.

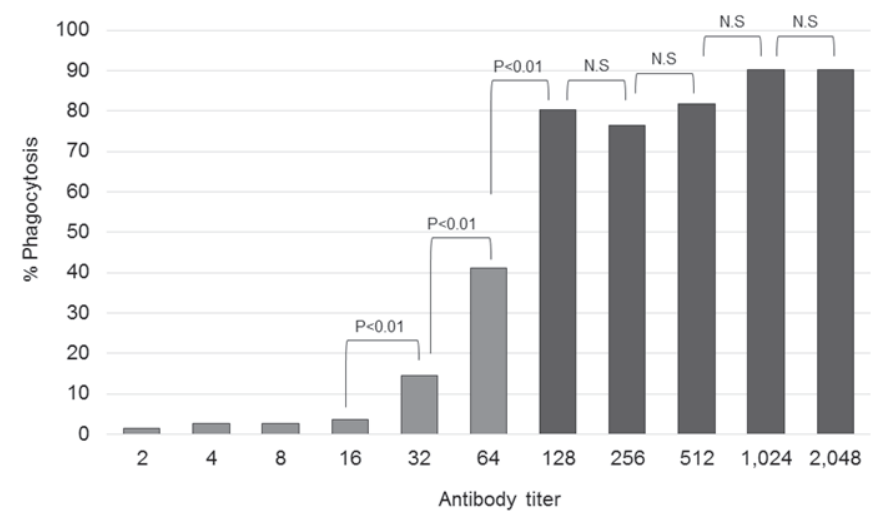

Figure 3: Trimmed mean of FCM-phagocytosis assay versus titers of 131 from 131 DAT-positive RBCs.

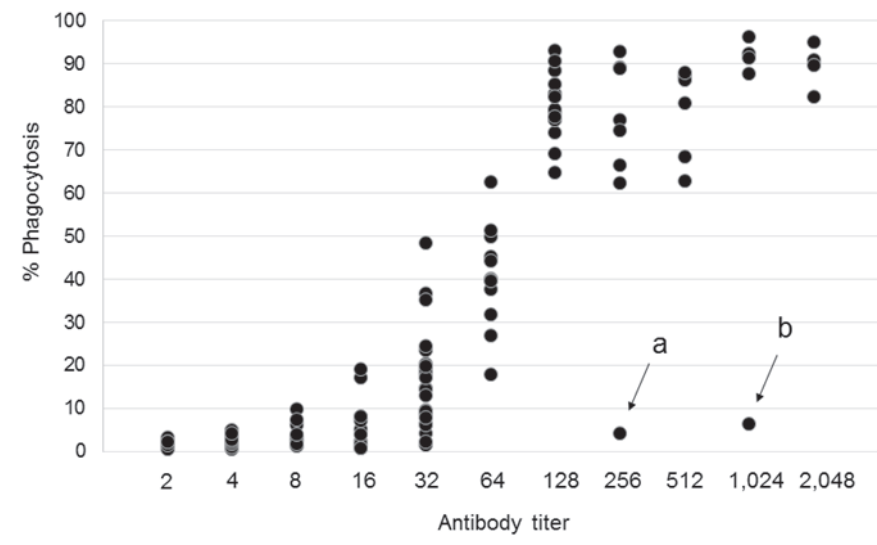

Figure 4: Percent FCM-phagocytosis versus titers of eluates from 131 DAT-positive RBCs. Samples of "a" and "b" were both of subclass IgG2.

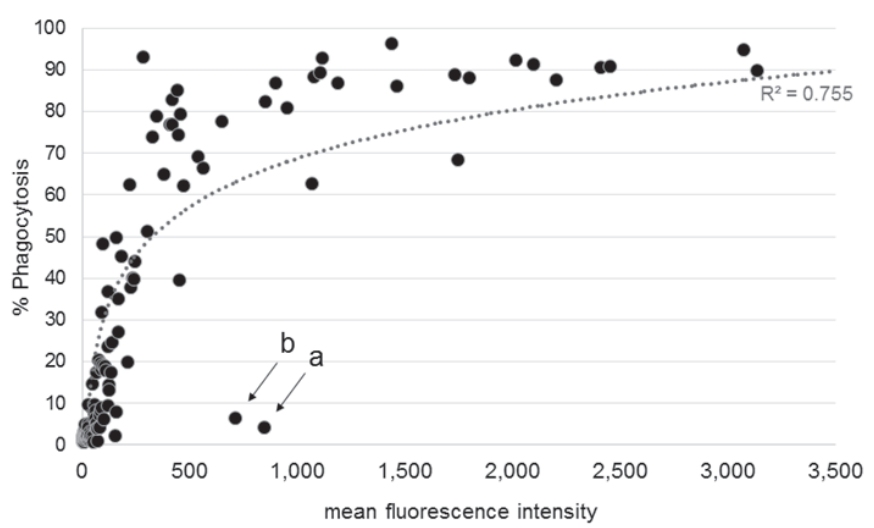

Figure 5: Percent FCM-phagocytosis versus mean fluorescence intensity of eluates from 131 DAT-positive RBCs. Samples of "a" and "b" were both of subclass IgG2.

\section{IgG subclass and FCM-phagocytosis activity}

IgG1 subclass predominated in 127 of 131 cases (97\%), singly in 60 cases (46\%) or in combination with IgG2, $\mathrm{IgG}_{3}$, and/or IgG4 subclasses in the remainder (Table 1). Total composition of subclasses was $96.9 \%$ of $\operatorname{IgG} 1$, $38.2 \%$ of $\operatorname{IgG} 2,26.7 \%$ of $\operatorname{IgG}_{3}$, and $12.2 \%$ of $\mathrm{IgG}_{4}$, as shown in Table 2.

Trimmed MFI of samples "a" and "b" of Figures 4 and 5 of single IgG2 subclass was 846.9 and 711.4 , respectively, which can be theoretically sufficientfor good FCM-phagocytosis activity. However, FCM-phagocytosis activities were low, at $4.1 \%$ and $6.2 \%$ (shown in Figures 4 and 5), respectively. Two other samples,predominantly IgG2 with lesser content of other subclasses, both at antibody titers of 32, showed lower phagocytic activity, $2.1 \%$ and $7.7 \%$, than the mean phagocytosis activity of $14.6 \%$ of others at the same titer, and comparable to trimmed-MFI values observed in the two samples.

Two cases with single IgG3 subclass titers of 2 and 16 did not show any increased phagocytic activity. Mixed subtypes including IgG3 were found in 34 cases (26\%), all which co-existed with a predominant IgG1, and showed no increased phagocytic activity.

\section{DISCUSSION}

FCM is more sensitive than tube or gel column agglutination for detecting RBC-bound IgG or complement, especially to diagnose DAT-positive autoimmune hemolytic anemia (AIHA) and to predict hemolysis in DAT-negative patients with AIHA [8-11]. The relative amounts of RBC-bound immunoglobulin and complement, and determination of IgG subclass, can be measured by FCM $[1,5,12]$. Monocyte monolayer assay using live monocytes is regarded as highly useful in determining the clinical significance of antibodies by observing phagocytosis of sensitized RBCs $[3,13,14]$.

In this report, we introduce a unique FCMphagocytosis assay, in which phagocytic activity of 
Table 1: Antibody titer of eluates and FCM-phagocytic assay

\begin{tabular}{|c|c|c|c|c|}
\hline Antibody titer & Number tested & $\begin{array}{l}\text { Phagocytic index } \\
\text { (trimmed mean) }\end{array}$ & $\begin{array}{l}\text { Phagocytic index } \\
\text { (minimum) }\end{array}$ & $\begin{array}{l}\text { Phagocytic index } \\
\text { (maximum) }\end{array}$ \\
\hline 2 & 14 & $1.4 \%$ & $0.5 \%$ & $3.2 \%$ \\
\hline 4 & 15 & $2.6 \%$ & $1.0 \%$ & $4.8 \%$ \\
\hline 8 & 15 & $2.7 \%$ & $1.1 \%$ & $9.7 \%$ \\
\hline 16 & 15 & $3.7 \%$ & $0.7 \%$ & $18.9 \%$ \\
\hline 32 & 23 & $14.6 \%$ & $1.4 \%$ & $48.2 \%$ \\
\hline 64 & 12 & $41.0 \%$ & $17.8 \%$ & $62.3 \%$ \\
\hline 128 & 13 & $80.4 \%$ & $64.7 \%$ & $93.0 \%$ \\
\hline 256 & 8 & $76.5 \%$ & $4.1 \% *$ & $92.6 \%$ \\
\hline 512 & 7 & $81.7 \%$ & $62.6 \%$ & $87.9 \%$ \\
\hline 1,024 & 5 & $90.3 \%$ & $6.2 \% *$ & $96.2 \%$ \\
\hline 2,048 & 4 & $90.2 \%$ & $82.2 \%$ & $94.8 \%$ \\
\hline
\end{tabular}

Table 2: Component ratio of IgG subclass

\begin{tabular}{lccc} 
IgG subclass & \multicolumn{2}{c}{ Number of cases (\%) } & Additional information \\
\hline $\mathrm{G} 1$ & 60 & $(45.8 \%)$ & \\
$\mathrm{G} 2$ & 2 & $(1.5 \%)$ & Antibody titer-256, and 1,024 \\
$\mathrm{G} 3$ & 2 & $(1.5 \%)$ & Antibody titer-2, and 16 \\
$\mathrm{G} 4$ & 0 & $(0 \%)$ & \\
$\mathrm{G} 1+\mathrm{G} 2$ & 25 & $(19.1 \%)$ & \\
$\mathrm{G} 1+\mathrm{G} 3$ & 11 & $(8.4 \%)$ & \\
$\mathrm{G} 1+\mathrm{G} 4$ & 5 & $(3.8 \%)$ & \\
$\mathrm{G} 1+\mathrm{G} 2+\mathrm{G} 3$ & 14 & $(10.7 \%)$ & \\
$\mathrm{G} 1+\mathrm{G} 2+\mathrm{G} 4$ & 3 & $(2.3 \%)$ & \\
$\mathrm{G} 1+\mathrm{G} 3+\mathrm{G} 4$ & 2 & $(5.3 \%)$ & \\
$\mathrm{G} 1+\mathrm{G} 2+\mathrm{G} 3+\mathrm{G} 4$ & 7 & 131 & \\
Total & &
\end{tabular}

an antibody can be quantified, by counting double positive events with RBC-bound PKH26 and monocytebound FITC after incubation of sensitized RBCs with live monocytes. In this study, we compared titers of autoantibodies eluted from RBCs of AIHA patients, and MFI against allogeneic RBCs and found MFI to be the strongestcorrelate of phagocytic response. Zupanska et al reported that $\mathrm{IgG}_{3}$ and $\mathrm{IgG}_{1}$ on RBC membranes were closely correlated to MMA results [15]. Dubarry et al concluded that warm (IgG) AIHA had three times the number of IgG molecules per RBC than DAT-positive RBCs with no hemolysis, and hemolysis correlated with higher numbers of antibodies on the RBC membrane [16]. In this study, we found that phagocytic activity correlated well with antibody titer, especially titers from 32 to 128 plateauing at 128 with a slight increase in phagocytic activity at higher titers.

As previously reported [3], IgG2 antibodies, with or without the incidental presence of other subclasses, brought about little phagocytic activity, because IgG2 and $\mathrm{IgG}_{4}$ antibodies are not efficiently recognized by the mononuclear phagocyte system.
We adapted FCM to evaluate antibody-mediated phagocytic activity, as FCM is well-established for its objectivity in measuring antibody intensity. At present, a weak point of FCM in this application is that cut-off values need to be established. In the standard MMA, positive, negative, and indeterminate values are set at $20 \%$ or more, $5 \%$ or less, and between $5.1 \%$ and $19.9 \%$, respectively [3]. In our previous study, the cut-off value for MMA was set at $1 \%$ [17]. In the present study, we investigated whether the FCM-phagocytosis assay correlates with standard MMA using 7 samples, and found that indeterminate values of MMA clustered around 50\% by FCM-phagocytosis, and tentatively propose cut-off values of $60 \%$ or more, $40 \%$ or less, and values in-between for positive, negative and indeterminate, respectively.

\section{CONCLUSION}

AIHA - associated antibodies can be evaluated with FCM phagocytosis assay. Additional studies of alloantibodies with and without clinical significance 


\section{EDORiUM Journals}

will refine our ability to anticipate clinical outcomes with a laboratory test, and establish cut-off values and correlation for patients with AIHA and other manifestations of disordered immunohematology.

\section{REFERENCES}

1. Klein HG, Anstee DJ. Mollison's Blood Transfusion in Clinical Medicine. 11ed. Oxford, UK: Blackwell Publishing; 2005. p. 90-1.

2. Kumpel BM, Beliard R, Brossard Y, et al. Section 1C: Assessment of the functional activity and IgG $\mathrm{Fc}$ receptor utilisation of $64 \mathrm{IgG} \mathrm{Rh}$ monoclonal antibodies. Coordinator's report. Transfus Clin Biol 2002 Jan; $9(1): 45-53$.

3. Arndt PA, Garratty G. A retrospective analysis of the value of monocyte monolayer assay results for predicting the clinical significance of blood group alloantibodies. Transfusion 2004 Sep;44(9):1273-81.

4. Bartolmäs T, Mayer B, Yürek S, Genth R, Salama A. Paradoxical findings in direct antiglobulin test and classification of agglutinating autoantibodies using eluates and monospecific anti-human globulin sera. Vox Sang 2015 Jan;108(1):58-63.

5. Asmussen C, Gutensohn K, Wittkopf D, Kühnl P. Rapid detection of IgG subclasses on DAT positive RBC membranes by flow cytometry (FC). Beitr Infusionsther Transfusionsmed 1996;33:35-9.

6. Lynen R, Neuhaus R, Schwarz DW, et al. Flow cytometric analyses of the subclasses of red cell IgG antibodies. Vox Sang 1995;69(2):126-30.

7. Tobita R, Aoyama N, Kaitou S. Production of four human monoclonal anti-D with constant-region recombinant subclasses of IgG1, IgG2, IgG3, or IgG4. Jpn J Transfus Cell Therapy 2016;62:314.

8. Lin JS, Hao TC, Lyou JY, et al. Clinical application of a flow cytometric direct antiglobulin test. Transfusion $2009 \mathrm{Jul} ; 49(7): 1335-46$.

9. Wang Z, Shi J, Zhou Y, Ruan C. Detection of red blood cell-bound immunoglobulin $\mathrm{G}$ by flow cytometry and its application in the diagnosis of autoimmune hemolytic anemia. Int J Hematol 2001 Feb;73(2):18893 .

10. Chaudhary R, Das SS, Gupta R, Khetan D. Application of flow cytometry in detection of red-cell-bound IgG in Coombs-negative AIHA. Hematology 2006 Aug;11(4):295-300.

11. Kamesaki T, Oyamada T, Omine M, Ozawa K, Kajii E. Cut-off value of red-blood-cell-bound IgG for the diagnosis of Coombs-negative autoimmune hemolytic anemia. Am J Hematol 2009 Feb;84(2):98-101.

12. Lynen R, Neuhaus R, Simson G, Riggert J, Köhler M. Flow cytometry analysis of IGG subclasses of autoand alloantibodies in autoimmune hemolytic anemia and hemolytic disease of the newborn. [Article in German]. Beitr Infusionsther Transfusionsmed 1994;32:203-7.

13. Nance SJ, Arndt P, Garratty G. Predicting the clinical significance of red cell alloantibodies using a monocyte monolayer assay. Transfusion 1987 NovDec;27(6):449-52.
14. Noumsi GT, Billingsley KL, Moulds JM. Successful transfusion of antigen positive blood to alloimmunised patients using a monocyte monolayer assay. Transfus Med 2015 Apr;25(2):92-100.

15. Zupanska B, Sokol RJ, Booker DJ, Stamps R. Erythrocyte autoantibodies, the monocyte monolayer assay and in vivo haemolysis. Br J Haematol 1993 May;84(1):144-50.

16. Dubarry M, Charron C, Habibi B, Bretagne Y, Lambin P. Quantitation of immunoglobulin classes and subclasses of autoantibodies bound to red cells in patients with and without hemolysis. Transfusion 1993 Jun;33(6):466-71.

17. Takeuchi C, Ohto H, Miura S, Yasuda H, Ono S, Ogata T. Delayed and acute hemolytic transfusion reactions resulting from red cell antibodies and red cell-reactive HLA antibodies. Transfusion 2005 Dec;45(12):19259.

$* * * * * * * * *$

\section{Author Contributions}

Shoichi Ito - Substantial contributions to conception and design, Acquisition of data, Drafting the article, Revising it critically for important intellectual content, Final approval of the version to be published

Tomoko Hishinuma - Substantial contributions to conception and design, Acquisition of data, Drafting the article, Final approval of the version to be published Yoshiko Ogiyama - Substantial contributions to conception and design, Acquisition of data, Drafting the article, Final approval of the version to be published Tomomi Asano - Substantial contributions to conception and design, Acquisition of data, Drafting the article, Final approval of the version to be published

Haruka Kagaya - Substantial contributions to conception and design, Acquisition of data, Drafting the article, Final approval of the version to be published

Michiyo Irino - Substantial contributions to conception and design, Acquisition of data, Drafting the article, Final approval of the version to be published

Hideya Hasegawa - Substantial contributions to conception and design, Acquisition of data, Drafting the article, Final approval of the version to be published Hiroshi Shimizu - Substantial contributions to conception and design, Acquisition of data, Drafting the article, Final approval of the version to be published

Kenneth E. Nollet - Analysis and interpretation of data, Drafting the article, Revising it critically for important intellectual content, Final approval of the version to be published

Masayoshi Minegishi - Substantial contributions to conception and design, Acquisition of data, Drafting the article, Revising it critically for important intellectual content, Final approval of the version to be published Hitoshi Ohto - Substantial contributions to conception and design, Analysis and interpretation of data, Drafting the article, Revising it critically for important intellectual content, Final approval of the version to be published 


\section{Guarantor of Submission}

The corresponding author is the guarantor of submission.

\section{Source of Support}

None

\section{Consent Statement}

Written informed consent was obtained from the patient for publication of this study.

\section{Conflict of Interest}

Authors declare no conflict of interest.

\section{Copyright}

(C) 2018 Shoichi Ito et al. This article is distributed under the terms of Creative Commons Attribution License which permits unrestricted use, distribution and reproduction in any medium provided the original author(s) and original publisher are properly credited. Please see the copyright policy on the journal website for more information.
Access full text article on other devices

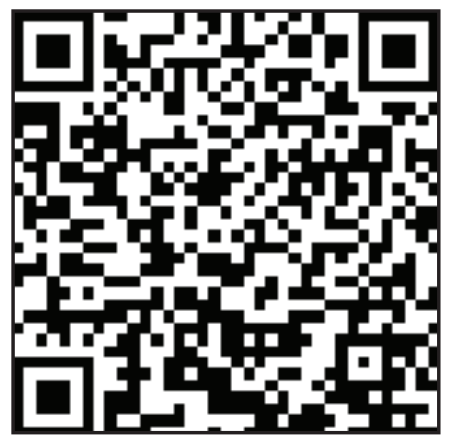

Access PDF of article on other devices

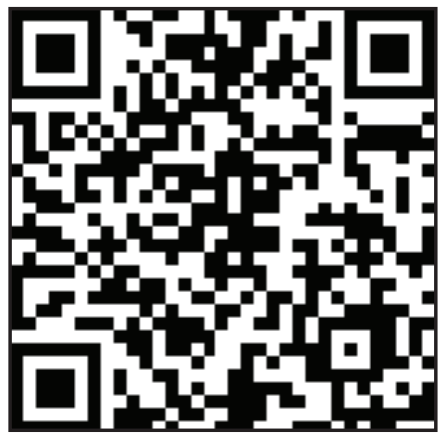

